\title{
SEDIMENTOS PROVENIENTES DE ESTRADAS DE USO FLORESTAL EM CONDIÇÃO DE RELEVO ONDULADO A FORTEMENTE ONDULADO
}

\author{
Carla Maria Camargo Corrêa ${ }^{1}$, Renato Antônio Dedecek ${ }^{2}$, Gláucio Roloff ${ }^{3}$ \\ ${ }^{1}$ Eng. Florestal, Dr., NIMAD/UFPR, Curitiba, PR, Brasil - camargocorrea@ufpr.br \\ ${ }^{2}$ Eng. Agrônomo, Ph.D., Embrapa Florestas, Colombo, PR, Brasil - dedecek@ cnpf.embrapa.br \\ ${ }^{3}$ Eng.Agrônomo, Ph.D., Itaipu Binacional, Foz do Iguaçu, PR, Brasil - groloff@pti.org.br
}

Recebido para publicação: 09/05/2008 - Aceito para publicação: 27/05/2009

\begin{abstract}
Resumo
Avaliaram-se, por um ano, as perdas de solos por enxurrada, em trechos de estradas secundárias e aceiros e a contribuição das áreas adjacentes, para estimar as perdas de solo em função da precipitação acumulada. Três tratamentos foram estabelecidos: num deles adotou-se medida de conservação, com implantação de barreiras de contenção de enxurrada a cada $50 \mathrm{~m}$ associadas a valas para deposição de sedimentos, adentrando nos talhões; os outros tratamentos compreendem trechos de estrada sem conservação e aceiros. Constataram-se os seguintes valores de perda de solo: 5,2 t.km ${ }^{-1}$ para o tratamento sem conservação, $4,1 \mathrm{t} . \mathrm{km}^{-1} \mathrm{em}$ estradas com conservação e $1,4 \mathrm{t} . \mathrm{km}^{-1} \mathrm{em}$ aceiros, totalizando 10,7 t.km ${ }^{-1}$ de perdas de solo acumulado no período. As medidas de conservação adotadas pela empresa reduziram as perdas de solo em 11,9\% nas Unidades de Manejo Florestal Ruthes e Leonel, em Itaiópolis (SC). A densidade de estradas apresentou-se dentro do limite máximo recomendado para efeito de certificação florestal $\left(59,92 \mathrm{~m} \cdot \mathrm{ha}^{-1}\right)$. Associado às condições de perfil longitudinal, sistema de drenagem e revestimento do leito estradal, aponta-se a necessidade de melhor dimensionamento das medidas de conservação e manutenção mais frequente. $\mathrm{O}$ controle da precipitação apresentou-se estatisticamente confiável na estimativa de perda de solo por erosão nas estradas avaliadas.

Palavra chave: Erosão hídrica; estrada florestal; perdas de solo; Pinus sp.
\end{abstract}

\begin{abstract}
Sediments proceeding from forest roads in wavy to strong waved relief conditions. For one year were evaluated, the soil losses by runoff proceeding to parts of fire breaks and secondary roads with it's respectively contribution areas, for estimative equations for soil losses in function of the accumulated precipitation. Tree treatments were established: roads with conservation measure, using water bars for control the runoff equidistant in 50 meters, associated with drain into the stands; roads without conservation and fire breaks. The soil losses as follow: $5,2{\underline{\mathrm{t}} \cdot \mathrm{km}^{-1}}^{-1}$ for roads without conservation

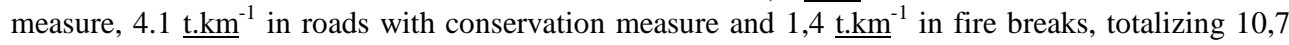
t.km-1 soil losses in the period. The conservation measures adopted had reduced the soil losses in $11,9 \%$ in the Forest Management Units Ruthes and Leonel - Itaiopolis / SC. The road density with $59,92 \mathrm{~m} \cdot \mathrm{ha}^{-1}$ just about the maximum limit recommended for forest certification. Associated to the longitudinal profile conditions, draining system and covering of the stream bed road, had pointed with respect to the necessity of better sizing of the conservation measures and more frequent maintenance. The control of precipitation was presented confidence statistical information for estimative the soil losses procceding from erosive process in the evaluated forest roads.
\end{abstract}

Keywords: Hydric erosion; forest road; soil loss and Pinus sp.

\section{INTRODUÇÃO}

A erosão hídrica se processa através do impacto das gotas de chuva, promovendo a desagregação das partículas do solo, sendo que a quantidade de material desagregado apresenta relação direta com a intensidade da precipitação, velocidade e volume das gotas. O material desagregado é transportado através da enxurrada para porções mais baixas da paisagem, provocando o assoreamento de corpos de 
água. Esse processo pode ser acelerado por fatores antrópicos, através da intervenção do homem no ambiente, seja na construção de estradas, seja na substituição da cobertura vegetal natural por monocultivos. Sá et al. (2004) mencionaram que os sedimentos erodidos contêm matéria orgânica, fertilizante, corretivos, sementes e até pesticidas aplicados pelos produtores. Depositados no leito dos rios, esses sedimentos provocam a diminuição da vazão devido ao assoreamento e aumentam o risco de enchentes, poluindo e contaminando corpos de água que podem afetar a saúde da população urbana dependente dessa água.

São consideradas estradas de uso florestal as que estão inseridas em UMFs, fazendo parte da rede viária básica, sendo utilizadas para as atividades de implantação, manutenção e conservação da floresta, ou pertencentes a rede viária complementar, cujo objetivo é atender as atividades de colheita de madeira, sendo portanto de utilização predominantemente florestal. A erosão do solo aparece como um problema central no diagnóstico ambiental em estradas de uso florestal, principalmente na implantação da rede viária complementar, em que alguns parâmetros técnicos e medidas de conservação acabam sendo negligenciados. Exemplo disso é a ineficiência de um sistema de drenagem associado à inexistência de controle e prevenção da erosão nessas estradas, que, ao serem submetidas ao tráfego pesado de máquinas e composições veiculares de carga, durante as operações de colheita e transporte de madeira, propiciam o escorrimento superficial e consequentemente assoreamento e poluição de mananciais (CAMARGO CORRÊA, 2005). Segundo Malinovski et al. (2004), o transporte de sedimentos e o consequente assoreamento de mananciais em áreas florestais estão diretamente relacionados aos seguintes fatores: (a) locação de estradas e caminhos e a qualidade de sua construção; (b) sistema de drenagem adequado e sua manutenção; (c) tipo de derrubada e retirada da madeira; e (d) nível de mecanização usado na realização de práticas silviculturais. Camargo Corrêa et al. (2005), Christopher (2002), Vital et al. (1999) e Ranzini (1990) advertem que essa situação se agrava durante a construção das estradas, devido à instabilidade causada pela retirada da cobertura vegetal, a movimentação do solo e a compactação de seu leito, assim como durante a sua utilização, devido ao tráfego pesado, tornando tais vias muito vulneráveis à erosão causada pela chuva.

No que se refere à produção de sedimentos, Luce (1993) propôs que, em se tratando de estradas de uso florestal, os sedimentos estão relacionados com outros fatores, tais como o tipo de solo, o comprimento e inclinação da rampa e a inclinação e altura dos taludes de corte e aterro. Dadalto et al. (1990) sugeriram que o aumento da declividade e o comprimento de rampa contribuem com as taxas de perda de solo por erosão, devido à aceleração da velocidade da enxurrada. Garcia et al. (2003), estudando erosão em estradas florestais, constataram que o volume de enxurrada foi mais afetado pelo comprimento do segmento, ao passo que a massa de solo sofreu maior influência da declividade, e a massa de solo erodido cresceu exponencialmente em função do incremento do volume de enxurrada. Já Lira Filho; Souza (1991) afirmam que o escoamento superficial em área florestal pode ser até três vezes maior na ocasião da colheita florestal.

Machado et al. (2003) recomendam que o procedimento mais comum para prevenir danos provocados pela erosão na estrada florestal é controlar o escoamento superficial da água das chuvas na faixa terraplenada da estrada. Camargo Corrêa (2005) sugere que o risco de erosão em estradas ocorre em função das características técnicas da estrada, tais como alinhamento horizontal e vertical, características do leito, sistema de drenagem e tipo de medida de conservação utilizado. Já o potencial erosivo reflete os efeitos combinados de erodibilidade e erosividade, que definirão qualitativamente e quantitativamente os sedimentos provenientes de estradas. Bertol et al. (2002) e Roloff; Denardin (1994) mencionaram que a erodibilidade do solo está diretamente relacionada com a suscetibilidade do solo a processos erosivos, e Souza et al. (2003) sugeriram que os fatores naturais mais importantes estão ligados ao clima, ao solo e à morfologia do terreno, associados a fatores antrópicos.

Diante do exposto, constitui-se objetivo do presente trabalho, avaliar o efeito da precipitação nas perdas de solo por enxurrada, proveniente de trechos de estradas secundárias e aceiros de uso florestal e suas respectivas áreas de contribuição, numa região de relevo ondulado a fortemente ondulado, para o ajuste de equação que estime as perdas de solo em função da precipitação acumulada.

\section{MATERIAL E MÉTODOS}

\section{Caracterização da área de estudo}

A área avaliada pertence a uma empresa produtora de celulose, papel e embalagens, localizada no Planalto Norte Catarinense, que utiliza macro e microplanejamento nas atividades de colheita e transporte florestal, aumentando e adaptando a rede viária em suas UMFs à medida que estas são 
submetidas às operações de colheita. Essas UMFs são caracterizadas em função das diferenciações entre si, decorrentes das características de sítio, produção, manutenção, preservação e sistema de colheita.

Os trechos de divisoras ou aceiros e estradas secundárias avaliadas não apresentam nenhum tipo de revestimento do leito e estão distribuídos em duas UMFs, Ruthes e Leonel, inseridas no município de Itaiópolis, em Santa Catarina, cuja localização geográfica é apresentada na figura 1.

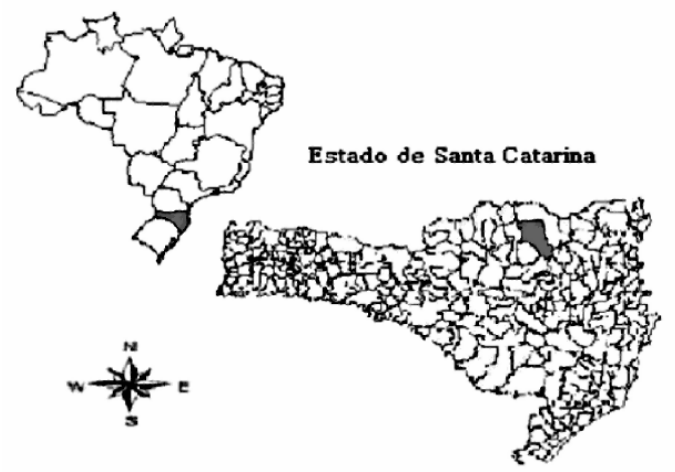

NOTAS: Município de Itaiópolis (SC) - 4954' W e 26²1' S; altitude: 1.004 m.

Figura 1. Localização das unidades de manejo florestal Ruthes e Leonel, avaliadas no município de Itaiópolis (SC).

Figure 1. Localization of forest management units Ruthes and Leonel, evaluated in municipal of Itaiópolis (SC).

Essas UMFs representam cerca de 5\% do total das áreas destinadas à produção florestal da empresa (PINTO, 2005) e apresentam diferenciações nas condições de relevo e características edáficas. $\mathrm{Na}$ figura 2 é ilustrada a disposição desses tratamentos.

O clima predominante nas regiões amostradas é do tipo Cfbl: temperado brando, chuvoso com verão fresco, segundo Köepen, com precipitação media anual de $1800 \mathrm{~mm}$, distribuída com maior frequência nos meses de dezembro a março, e em menor quantidade nos meses de junho a agosto. A temperatura média anual é de $18{ }^{\circ} \mathrm{C}$, com médias mínimas alcançadas de $7{ }^{\circ} \mathrm{C}$ e médias máximas de $26{ }^{\circ} \mathrm{C}$ (CAMARGO CORRÊA, 2005).

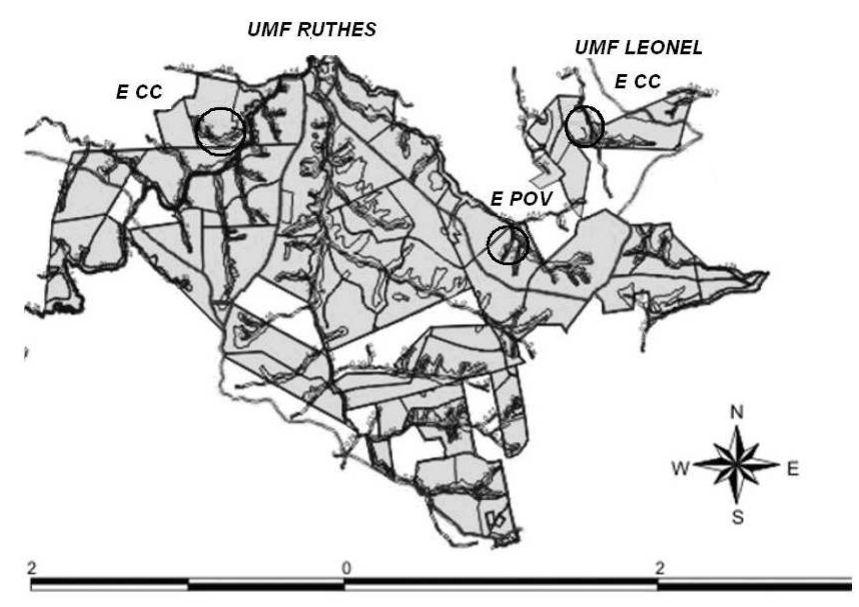

Notas:

UMF RUTHES

UMF LEONEL

Estradas amostradas

E CC = Estrada com conservação com sua respectiva área de contribuição com conservação C CC

$\mathrm{E} \mathrm{SC}=$ Estrada sem conservação com sua respectiva área de contribuição sem conservação C SC.

$\mathrm{E} P O V=$ Estrada do povoamento com sua respectiva área de contribuição do povoamento C POV.

Figura 2. Trechos de estradas avaliados nas unidades de manejo florestal no município de Itaiópolis (SC).

Figure 2. Parts of the forest roads evaluated at forest management units located in Itaiopolis (SC). 


\section{Coleta de dados}

O monitoramento dos trechos de estradas avaliados teve início em março de 2003 e término em junho de 2004. Durante esse período, foram coletados quinzenalmente os sedimentos sólidos que ficaram retidos nas calhas e os sedimentos em suspensão em água armazenada nos baldes que eram conectados às calhas através de cano, juntamente com as informações de precipitação, obtidas através de pluviógrafo instalado no município avaliado.

De acordo com o Mapa Geológico do Estado de Santa Catarina (1986), essas UMFs estão sobre a seguinte formação geológica: Paleozóico/Permiano/médio e inferior. Unidade litoestatigráfica: Subgrupo: Tubarão/Grupo: Guatá - Prb/Formação: Rio Bonito. Litologia e ambiente: Seção média: sedimentos marinhos, compreendendo siltitos e folhelhos esverdeados com níveis carbonáticos argilosos silicificados em superfície e subordinadamente arenitos muito finos. Seção inferior: depósito fluviodeltaítico, compreendendo arenitos imaturos arcóseos e subarcóseos, esbranquiçados, finos a médios, localmente grosseiros, argilosos micáceos e secundariamente arenitos muito finos, siltitos e argilitos, folhelhos carbonosos, leito de carvão e conglomerado.

As UMFs avaliadas apresentam solos pertencentes às seguintes classes: Argissolos, Cambissolos e Neossolos, sendo que os Argissolos e Neossolos estão restritos a algumas posições na paisagem. No entanto, as áreas amostradas estão sobre as seguintes classes de solo: Cambissolo Húmico, Distrófico típico, A húmico, álico, textura média, relevo ondulado. Nessa classe de solo foram instalados os tratamentos que representam trechos de estrada com conservação e a estrada do povoamento ou divisoras, com suas respectivas áreas de contribuição. Essa classe representa a maior ocorrência observada na propriedade. Argissolo Vermelho-Amarelo Distrófico típico, A proeminente álico, textura argilosa, relevo ondulado. Esse tipo de solo está localizado em situações de maior declividade, onde estão instalados os tratamentos que representam o trecho de estrada sem conservação e sua respectiva área de contribuição.

As amostras de solo coletadas nas UMFs apresentaram estrutura predominantemente granular, com grau de desenvolvimento moderado ou forte, podendo encontrar estrutura maciça e coesa devido à mecanização. A textura variou entre média e arenosa (350 a $80 \mathrm{~g} . \mathrm{kg}^{-1}$ de argila), pertencente às classes franco arenosa, franco argilosa, arenosa ou argilosa com altos teores de silte. Nas áreas amostradas sobre Cambissolos, foi constatada textura média com $59,9 \%$ de areia total, $16,1 \%$ de silte e $24 \%$ de argila no horizonte A, e nos Argissolos constatou-se textura predominantemente argilosa nas seguintes proporções: $8,7 \%$ de areia total, $43,3 \%$ de silte e $48 \%$ de argila no horizonte A (CAMARGO CORRÊA, 2005).

As condições de relevo encontradas nas áreas pertencem às classes ondulado a fortemente ondulado, com interflúvios curtos e levemente aplanados, encostas declivosas com pendentes longas. No entanto, as declividades horizontais máximas encontradas nos trechos de estradas avaliados nas UMFs variaram de $12 \%$ a $15 \%$, e nas suas respectivas áreas de contribuição variaram de $12 \%$ a $16 \%$, no sentido do declive.

Utilizou-se neste trabalho calha coletora de solo conhecida como amostrador de enxurrada tipo Coshocton (PARSONS, 1954), para determinação do volume de solo e água perdidos através de escorrimento superficial. Os sedimentos grosseiros ficam retidos na calha e apenas $1 \%$ do volume total de água com sedimentos é direcionado para recipientes coletores (baldes com capacidade de 62 1), conectados através de cano, cujos detalhes podem ser observados na figura 3.

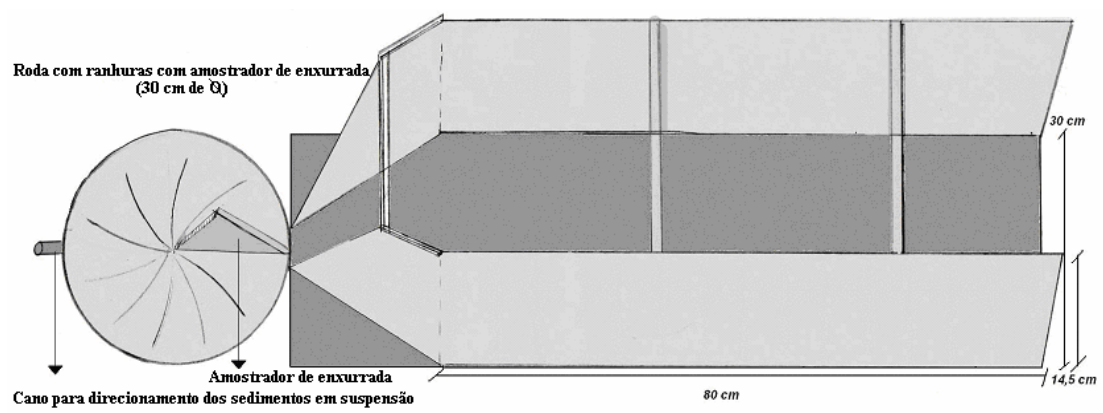

Figura 3. Detalhes do amostrador de enxurrada tipo Coshocton.

Figure 3. Details of Cochocton runoff sampler. 
Os sedimentos retidos nas calhas coletoras foram recolhidos, pesados e avaliados quinzenalmente durante o período de monitoramento, sendo submetidos a análise granulométrica. A textura foi determinada através do método da pipeta, no Laboratório de Física, pertencente ao Departamento de Solos e Engenharia Agrícola da UFPR, que segue a metodologia proposta pela EMBRAPA (1997).

O sistema viário nas UMFs contempla a seguinte distribuição: $32,37 \mathrm{~km}$ de estradas primárias e secundárias, com densidade de 24,31 m.ha ${ }^{-1}, 23,72 \mathrm{~km}$ de divisoras ou aceiros internos, com densidade de 17,82 m.ha ${ }^{-1}$, e 23,69 km de contorno ou aceiros externos, com densidade de 17,79 m.ha ${ }^{-1}$, compondo um total 59,92 m.ha ${ }^{-1}$, de acordo com o relatório final do processo de certificação pelo CERFLOR, apresentado por Pinto (2005). Nesse trabalho estão sendo considerados os seguintes critérios de classificação de estradas: estrada primária, quando apresenta revestimento primário constituído de material sedimentar presente na região, folhelho, saibro ou cascalho, e sistema de drenagem; estradas secundárias, que, em sua maioria, não apresenta nenhum tipo de revestimento, somente a compactação do leito e sistema de drenagem, ainda que em alguns trechos críticos sejam empregadas medidas de conservação em estradas, como parte do código de prática da empresa, a ser melhor detalhado na sequência. Já os aceiros internos e externos são submetidos a roçadas periódicas.

\section{Amostragem}

Este trabalho contemplou três tratamentos em estradas, sendo dois trechos de estradas secundárias e um trecho de divisora ou aceiro, e três tratamentos em áreas de contribuição, que compreendem amostragens de 0,5 ha nas áreas adjacentes aos trechos de estradas avaliadas, visando identificar o potencial de contribuição destas nas perdas totais de solo nas áreas avaliadas.

As dimensões das parcelas nos trechos de estradas foram de 100 metros de comprimento de estrada com largura média de 6 metros (nas divisoras ou aceiros a largura média foi de 4 metros). Essas parcelas foram delimitadas por linhas de drenagem nas laterais das estradas e por barreiras de contenção nas extremidades, cuja função foi evitar o acréscimo de sedimentos oriundos de outros segmentos da estrada. As parcelas foram também protegidas por lonas pretas nas laterais, a fim de evitar a deposição de sedimentos provenientes das suas respectivas áreas de contribuição. Na porção mais baixa da parcela, seguindo a linha de drenagem da estrada, foram instaladas calhas coletoras de solo. Na figura 4 estão expostos alguns detalhes de um trecho de estrada com medidas de conservação.

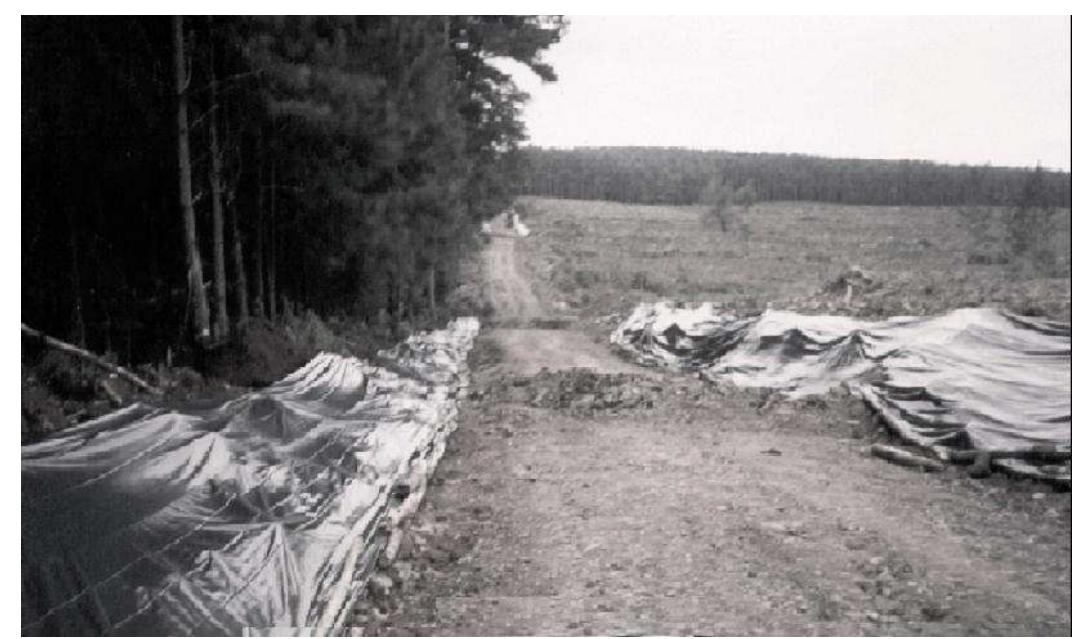

Figura 4. Detalhes de um dos trechos de estrada monitorado.

Figure 4. Details in one part of road monitored.

Foram considerados os seguintes tratamentos de estrada: estradas com conservação (E CC), trechos de estradas com a implementação de medidas de conservação adotadas pela empresa, que contemplam a adoção de barreiras de contenção da enxurrada associadas às valas de retenção de água e sedimentos, equidistantes aproximadamente 50 metros, e ausência de revestimento do leito carroçável. 
Cada parcela apresentou três barreiras de contenção de enxurrada, sendo uma em cada extremidade e uma central, associada à vala de retenção de água.

As estradas sem conservação (E SC) compreenderam trechos de estradas sem medidas de conservação e estradas no povoamento (E POV), representadas por trechos das divisoras ou aceiros, que são submetidos a roçadas periódicas e, no momento da colheita, utilizados como vias de acesso.

As áreas de contribuição foram demarcadas a partir da porção mais alta, localizadas próximas aos trechos de estradas amostrados, tendo sido identificadas da seguinte forma: área de contribuição adjacente à estrada com conservação $(\mathrm{C} C \mathrm{C})$ e área de contribuição adjacente à estrada sem conservação (C SC). Essas áreas contemplaram novos plantios, submetidas a preparo convencional do solo utilizado pela empresa, que consiste em enleiramento de resíduos e preparo do solo com uso de subsolador morro abaixo, prática adotada pela empresa para aquela condição de solo e relevo. A área de contribuição do povoamento (C POV), adjacente ao trecho aceiro E POV, foi demarcada em um povoamento de Pinus taeda com idade de 8 anos, cuja dimensão da área amostrada correspondeu a 50 x $100 \mathrm{~m}(0,5$ ha), delimitada por linhas de drenagem, onde foram instaladas as calhas coletoras de solo, na porção mais baixa da paisagem. Na figura 5, está disposto o lay-out do tratamento de estrada com conservação (E CC) e sua respectiva área de contribuição $(\mathrm{C} C \mathrm{C})$, para exemplificar o arranjo dos tratamentos propostos.

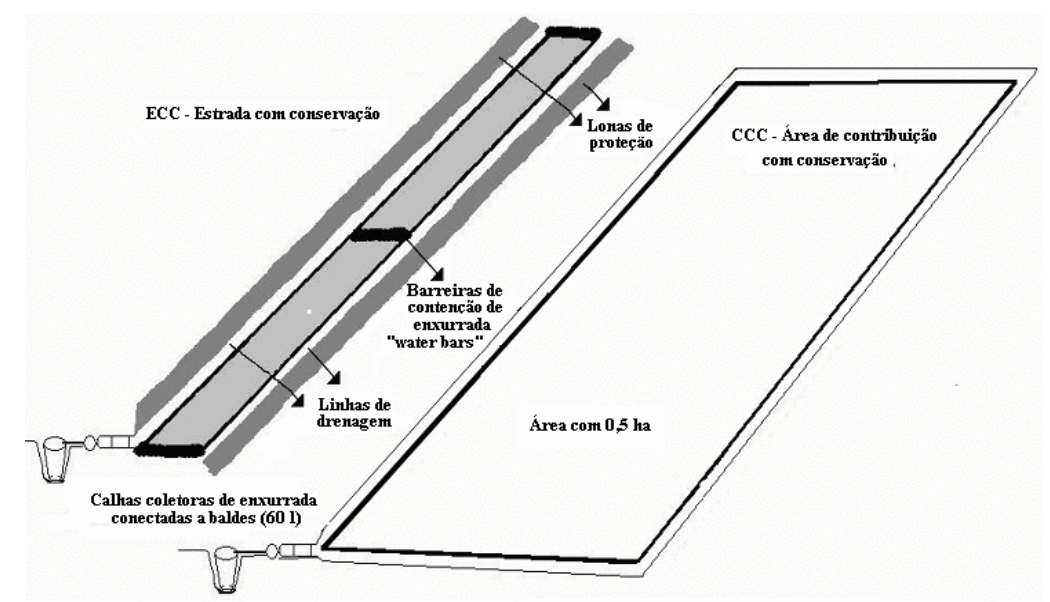

Figura 5. Lay-out dos tratamentos estrada com conservação (E CC) e área de contribuição com conservação (C CC) nas UMFs de Itaiópolis (SC).

Figure 5. Lay-out of treatments in parts of forest roads with conservation (E CC) and contribution areas with conservation (C CC) at FMUs in Itaiópolis (SC).

A legenda dos tratamentos, juntamente com as informações de declividade horizontal máxima de cada amostragem e as coordenadas georreferenciadas estão expostas na tabela 1.

Tabela 1. Legenda dos tratamentos avaliados nas duas unidades de manejo florestal.

Table 1. Legend of treatments evaluated at two forest management units.

\begin{tabular}{|c|c|c|c|c|}
\hline Município & Tratamento & Legenda & Decliv. (\%) & Coordenadas georreferenciadas \\
\hline Itaiópolis & Estrada com conservação & ITA/E/CC & 12 & $\begin{array}{c}\text { Início } 619,485.39-7,081,053.59 \\
\text { Final } 619,584.79-7,081,116.99\end{array}$ \\
\hline Itaiópolis & Estrada sem conservação & ITA/E/SC & 13 & $\begin{array}{c}\text { Início 616,864.96 - 7,082,416.64 } \\
\text { Final } 616,960.06-7,082,374.37\end{array}$ \\
\hline Itaiópolis & Estrada povoamento & ITA/E/POV & 15 & $\begin{array}{c}\text { Início } 620,383.53-7,082,427.20 \\
\text { Final } 620,480.89-7,082,427.20\end{array}$ \\
\hline Itaiópolis & Contribuição com conservação & ITA/C/CC & 1 & Central 619,495.96 - 7,081,138.12 \\
\hline Itaiópolis & Contribuição sem conservação & ITA/C/SC & 12 & Central 616,864.96 - 7,082,458.90 \\
\hline Itaiópolis & Contribuição povoamento & ITA/C/POV & 16 & Central $620,436.36-7.082,480,03$ \\
\hline
\end{tabular}


Os resultados de perdas de sedimentos por processos erosivos obtidos durante o monitoramento foram submetidos à análise estatística de Regressão Linear através do programa computacional STATISTICA, versão 5 .

\section{Erosividade e erodibilidade}

A erosividade da chuva (ou fator R) foi determinada em função do índice de erosividade, que considera a intensidade máxima da chuva em 30 minutos, expresso em MJ.mm.ha ${ }^{-1} \cdot \mathrm{h}^{-1} \cdot \mathrm{ano}^{-1}$.

$$
\mathrm{EI}_{30}=\mathrm{E} . \mathrm{I}_{30}
$$

Em que:

$\mathrm{EI}_{30}=$ índice de erosividade da chuva em 30 minutos;

$\mathrm{E}$ = energia cinética da chuva, calculada através do método de Wischmeier; Smith (1958);

$\mathrm{I}_{30}=$ intensidade máxima de chuva em 30 minutos.

O fator R é obtido através da soma dos valores mensais do índice de erosividade.

$$
\mathrm{R}=\sum \mathrm{EI}_{30}^{12} \mathrm{~J}=1
$$

A erodibilidade do solo (ou fator $\mathrm{K}$ ) foi determinada de acordo com a equação proposta por Denardin (1990).

$$
K=0,00608 c+0,00834 a-0,00116 d-0,00038 e
$$

Em que:

$\mathrm{K}=$ erodibilidade do solo (t.h. $\mathrm{MJ}^{-1} \cdot \mathrm{mm}^{-1}$ ), sendo a e c constantes;

$\mathrm{d}=$ teor de $\mathrm{A}^{2} \mathrm{O}^{3}$, extraído por ácido sulfúrico $(\%)$;

$\mathrm{e}=$ teor de partículas entre 2,0 e $0,5 \mathrm{~mm}(\%)$ (areia grossa: 2,0-0,2 $\mathrm{mm}$ )

Os fatores $\mathrm{L}$ e $\mathrm{S}$ foram medidos em campo, e os demais estimados de acordo com as proposições de Dissmeyer; Foster (1980).

\section{RESULTADOS E DISCUSSÃO}

As duas regiões avaliadas apresentaram distribuição pluviométrica equilibrada, com $8 \%$ a $10 \%$ da precipitação anual verificados em todos os meses, ocorrendo excedente hídrico nos meses pertencentes à estação do verão e inexistência de déficit hídrico. A precipitação mínima mensal correspondeu a 36,2 $\mathrm{mm}$ em agosto de 2003 , e a máxima de $189,8 \mathrm{~mm}$ no mês de dezembro do mesmo ano. A precipitação média foi de $98,1 \mathrm{~mm}$, e a acumulada durante o período de monitoramento foi de 1.495,6 mm, conforme a figura 6, que apresenta a distribuição quinzenal e mensal da precipitação nas áreas avaliadas durante o período de monitoramento.

A precipitação é o agente ativo no processo de erosão, por desagregar as partículas de solo e promover o transporte de sedimentos. Em todos os meses de monitoramento, os pluviógrafos registraram eventos de chuva com intensidade superior a $10 \mathrm{~mm} \cdot \mathrm{h}^{-1}$, que apresenta potencial erosivo, totalizando 30 eventos durante o período de avaliação. A chuva com potencial erosivo acumulada no período de avaliação nas UMFs de Itaiópolis foi de 1.495,6 mm, correspondendo a uma erosividade de 9.061,8 MJ.mm.ha ${ }^{-1} \cdot h^{-1} \cdot a n o^{-1}$, valor superior aos encontrados por Bertol (1994) na região de Campos Novos (SC), que apresentou 6.329,3 MJ.mm.ha ${ }^{-1} \cdot \mathrm{h}^{-1} \cdot \mathrm{ano}^{-1}$, e em Lages (SC), com $5.694 \mathrm{MJ} \cdot \mathrm{mm} \cdot \mathrm{ha}^{-1} \cdot \mathrm{h}^{-1} \cdot \mathrm{ano}^{-1}$ (BERTOL, 1994). Essa diferença pode ser atribuída ao fato de que a amostragem foi efetuada sob o efeito "El Niño", que provoca mudanças na dinâmica geral da atmosfera, alterando o comportamento climático e provocando chuvas acima da média nos estados da região Sul. De acordo com Neves et al. (2008), valores médios de erosividade da chuva estão em torno de $7.000 \mathrm{MJ} \cdot \mathrm{mm} \cdot \mathrm{ha}^{-1} \cdot \mathrm{h}^{-1} \cdot \mathrm{ano}^{-1}$.

$\mathrm{O}$ fator erodibilidade do solo $(\mathrm{K})$ variou entre 0,036 e 0,025 t.ha.h.ha ${ }^{-1} \cdot \mathrm{MJ}^{-1} \cdot \mathrm{mm}^{-1}$ nos Cambissolos e de 0,038 a 0,025 t.ha.h.ha ${ }^{-1} \cdot \mathrm{MJ}^{-1} \cdot \mathrm{mm}^{-1}$ nos Argissolos Vermelho Amarelo. Foster et al. (1981) sugerem três classes para os valores do fator erodibilidade do solo (K), enquanto que Mannigel $e t$ al. (2002) propõem seis classificações para esse fator, conforme tabela 2. 


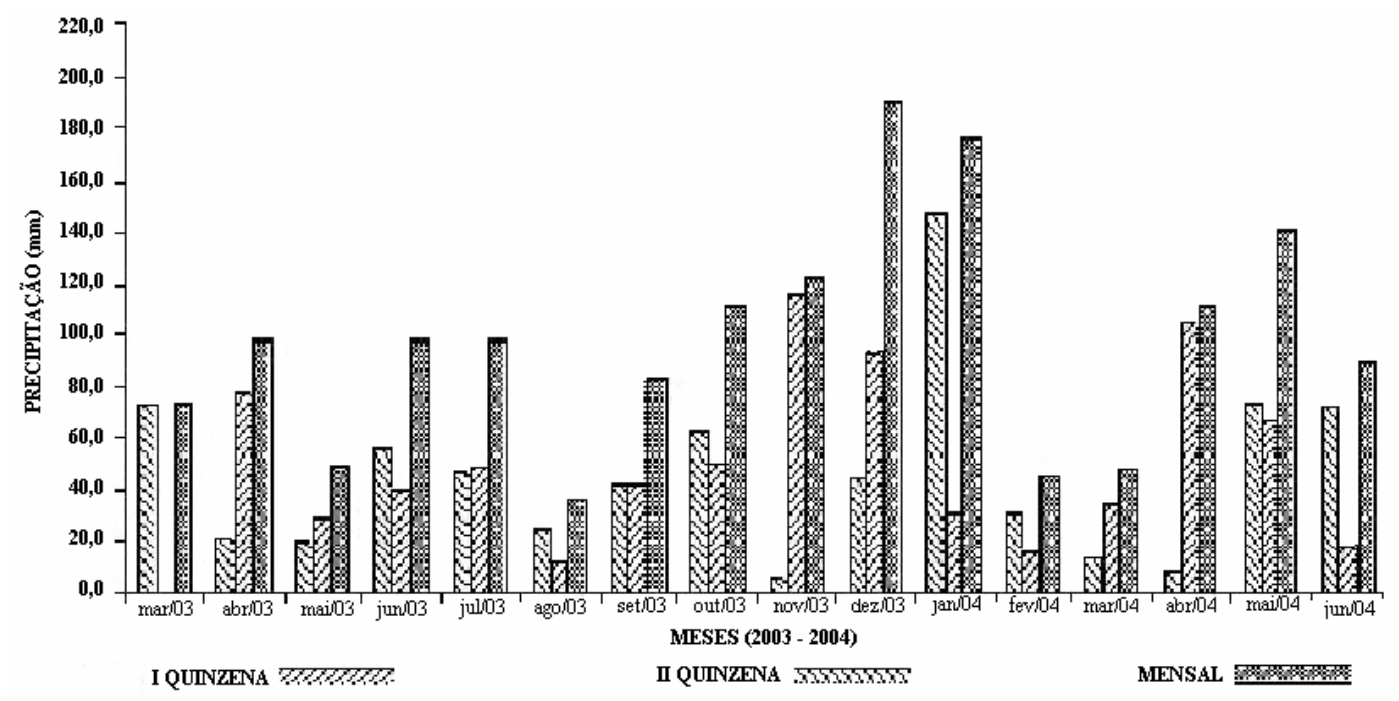

Figura 6. Precipitação (mm) quinzenal e mensal em Itaiópolis (SC).

Figure 6. Biweekly and monthly precipitation in Itaiopolis (SC).

Tabela 2. Classificação para fator de erodibilidade do solo.

Table 2. Classification for soil erodibility factor.

\begin{tabular}{|c|c|c|c|c|c|c|c|c|}
\hline \multicolumn{9}{|c|}{ Fator erodibilidade do solo K (t.ha.h.ha ${ }^{-1} . \mathrm{MJ}^{-1} \cdot \mathrm{mm}^{-1}$ ) } \\
\hline \multicolumn{3}{|c|}{ Foster et al. (1981) } & \multicolumn{6}{|c|}{ Mannigel et al. (2002) } \\
\hline Baixo & médio & alto & $\begin{array}{l}\text { Extremamente } \\
\text { alto }\end{array}$ & Muito alto & Alto & Médio & Baixo & $\begin{array}{l}\text { Muito } \\
\text { baixo }\end{array}$ \\
\hline $\begin{array}{l}0,01 \mathrm{e} \\
0,03\end{array}$ & $\begin{array}{c}0,03 \mathrm{e} \\
0,06\end{array}$ & $>0,06$ & $>0,060$ & $\begin{array}{c}0,060 \mathrm{e} \\
0,045\end{array}$ & $\begin{array}{c}0,045 \mathrm{e} \\
0,030\end{array}$ & $\begin{array}{c}0,030 \mathrm{e} \\
0,015\end{array}$ & $\begin{array}{c}0,015 \mathrm{e} \\
0,009\end{array}$ & $<0,009$ \\
\hline
\end{tabular}

De acordo com as classificações propostas, os valores de erodibilidade do solo encontrados tanto para os Cambissolos como para os Argissolos encontram-se de baixo a médio, segundo Foster et al. (1981), e de médio a alto, de acordo com Mannigel et al. (2002).

A análise quantitativa dos sedimentos forneceu informações sobre o volume acumulado de sedimento perdido por tratamento, sendo expresso em t.km ${ }^{-1}$ nos trechos de estradas e em t.ha ${ }^{-1}$ nas respectivas áreas de contribuição avaliadas. Os sedimentos procedentes dos trechos de estrada avaliados foram confrontados com a precipitação acumulada, expressa em $\mathrm{mm}$, constatando-se as perdas provenientes de cada tratamento avaliado em t.km ${ }^{-1}$, conforme pode se observar na figura 7 .

$\mathrm{O}$ volume total das perdas de sedimento provenientes dos trechos de estradas avaliados foi de 10,7 t.km${ }^{-1}$ no período, que apresentou a seguinte distribuição entre os tratamentos: (a) o trecho de estrada com medidas de conservação (E CC) representou cerca de 38,0\% das perdas totais de sedimentos, com volume total de $4,1 \mathrm{t}_{\mathrm{km}} \mathrm{-1}^{3}$ de perda de solo durante o período; (b) o trecho de estrada sem medidas de conservação (E SC) apresentou 48,9\% das perdas totais de sedimentos por processo erosivo durante o período, com perdas de solo de $5,2 \mathrm{t}_{\mathrm{km}} \mathrm{km}^{-1}$; e (c) o trecho de estrada do povoamento (E POV) contribuiu com $13,1 \%$ das perdas totais de solo durante o período, correspondendo a $1,4 \mathrm{t} . \mathrm{km}^{-1}$. Quando comparados apenas os tratamentos E CC e E SC, constata-se que as medidas de conservação de estradas utilizadas pela empresa foram eficientes no controle das perdas de solo em 11,9\% para as condições avaliadas.

Os valores de perda de solo acumulada no período foram submetidos a análise de regressão, através do programa STATISTICA, considerando a precipitação como variável independente, numa amostragem de 30 elementos, equivalente às coletas de solo nos períodos em que houve chuva com potencial erosivo. Os resultados provenientes dessa análise estatística encontram-se apresentados na tabela 3 . 


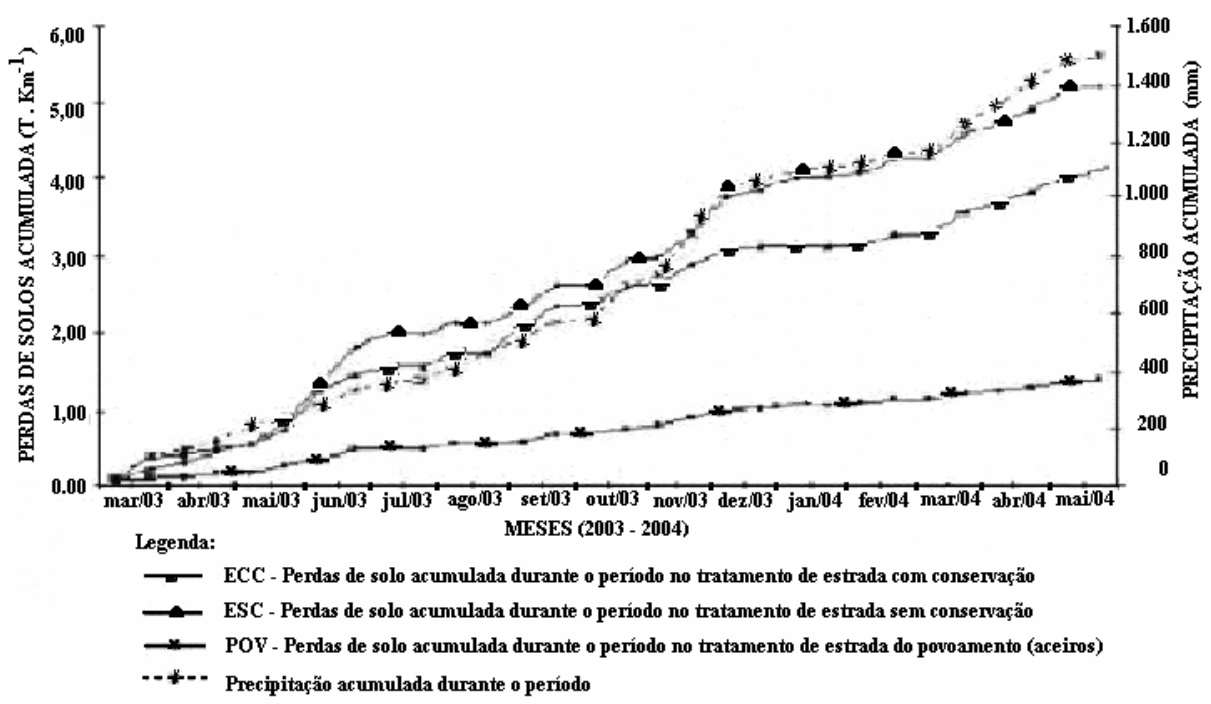

Figura 7. Precipitação acumulada $(\mathrm{mm})$ versus perdas de solos acumuladas provenientes dos trechos de estradas avaliados nas UMFs de Itaiópolis (SC).

Figure 7. Cumulated precipitation $(\mathrm{mm})$ versus cumulated soil losses originated from parts of forest roads evaluated in FMUs in Itaiopolis (SC).

Tabela 3. Análise estatística para os trechos de estrada avaliados nas UMFs de Itaiópolis (SC).

Table 3. Statistical analyses for parts of forest roads evaluated at FMUs in Itaiopolis (SC).

\begin{tabular}{lcccccc}
\hline Tratamento & Equação & $\mathbf{R}(\boldsymbol{\%})$ & $\mathbf{R}^{\mathbf{2}(\%)}$ & $\mathbf{F ~ ( 1 , 2 8 )}$ & $\mathbf{p}$ & Erro padrão \\
\hline $\mathrm{E} \mathrm{CC}$ & $\mathrm{ITA} / \mathrm{E} / \mathrm{CC}=0,4215+0,0026 * \mathrm{x}$ & 97,6 & 95,2 & 554,51 & $<0,001$ & 0,2713 \\
$\mathrm{E} \mathrm{SC}$ & $\mathrm{ITA} / \mathrm{E} / \mathrm{SC}=0,2982+0,0034 * \mathrm{x}$ & 98,6 & 97,2 & 977,5 & $<0,001$ & 0,2741 \\
$\mathrm{E}$ POV & $\mathrm{ITA} / \mathrm{E} / \mathrm{POV}=0,0962+0,0014 * \mathrm{x}$ & 99,5 & 98,9 & 2575,2 & $<0,001$ & 0,0682 \\
\hline
\end{tabular}

x: variável precipitação acumulada no período.

O controle da precipitação apresentou resultados com elevada significância estatística, em função dos altos valores de $\mathrm{F}(1,28)$ e p inferior a 0,001 , observados em todos os tratamentos que contemplaram as perdas de solo provenientes dos trechos de estradas monitoradas durante o período, em um intervalo de confiança de $95 \%$. A análise de correlação apresentou resultados positivos entre a precipitação e as perdas de solo proveniente dos trechos de estradas avaliados durante o período, variando de $97,6 \%$ a praticamente $100 \%$. O coeficiente de determinação $\mathrm{R}^{2}(\%)$, proposto pelas equações obtidas através da análise de regressão para os tratamentos de estradas, foi capaz de explicar entre 95,2\% e 98,9\% as variações de perdas de solo acumuladas durante o período em função da precipitação acumulada, com baixos níveis de erro padrão de estimativa, o que evidencia o bom ajuste da equação proposta. A figura 8 expressa a análise de regressão linear obtida entre os tratamentos do comportamento das perdas de solo provenientes dos trechos de estradas avaliadas durante o período em função da precipitação.

Associando-se os valores de perda de solo com a densidade de estradas dessas UMFs e as medidas de conservação adotadas pela empresa, concluiu-se que as perdas de solo provenientes de estradas corresponderiam a 198 t.ano $^{-1}$, se todos os trechos dessas estradas apresentassem medidas de conservação. No entanto, se essas estradas não apresentassem medidas de conservação, esse valor aumentaria para 236 t.ano $^{-1}$ de solo perdido por erosão. Nas áreas destinadas a aceiros ou divisoras, as perdas de solo corresponderam a 66 t.ano ${ }^{-1}$.

Os valores de perda de solo acumulada durante o período nas respectivas áreas de contribuição dos trechos das estradas avaliados estão expressos em t.ha ${ }^{-1}$, e a precipitação acumulada em mm, conforme ilustrado na figura 9. 
E CC - Estrada com Conservação / Forest Roads with Conservation

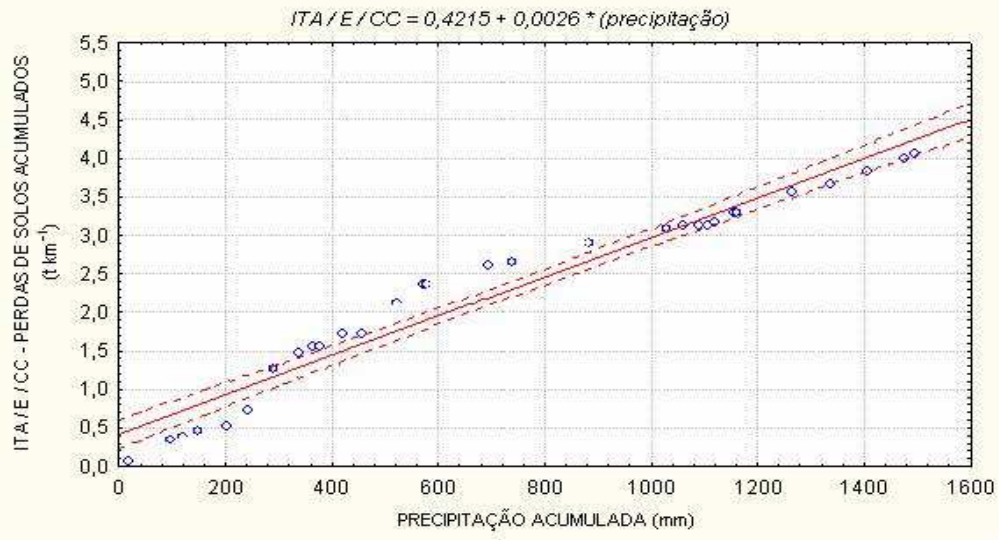

E SC - Estrada sem Conservação / Forest Roads without Conservation

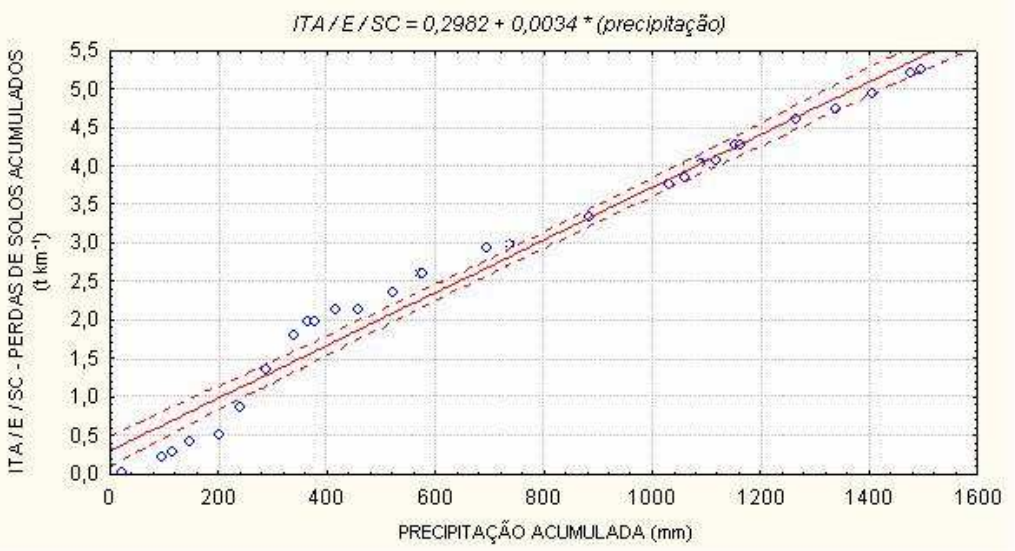

E Pov - Estrada do Povoamento / Fire Breaks

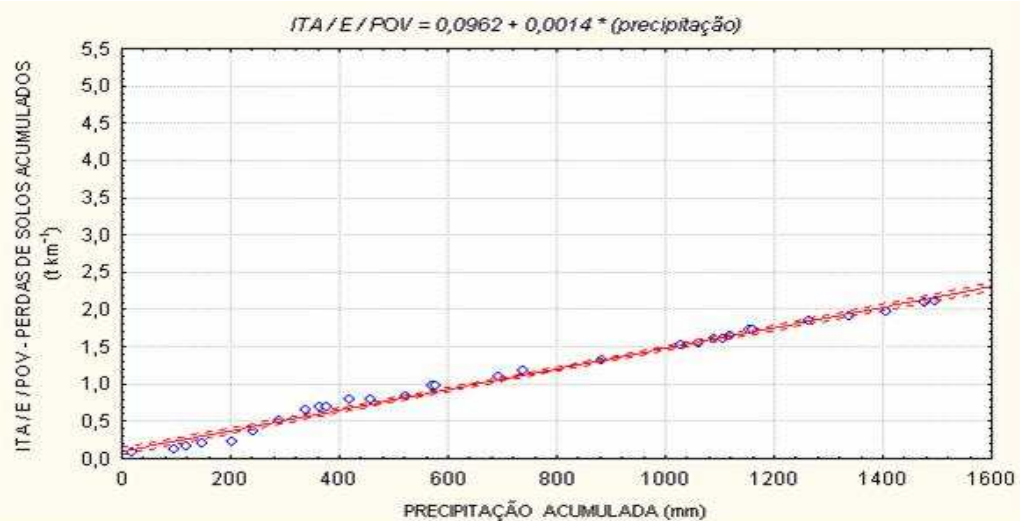

Figura 8. Precipitação acumulada versus perdas de solo acumuladas no trecho de estrada avaliados nas UMFs de Itaiópolis (SC).

Figure 8. Accumulated precipitation versus accumulated soil losses in parts of forest roads evaluated at FMUs in Itaiopolis (SC).

As áreas de contribuição adjacentes aos trechos de estradas avaliados estão representadas pela legenda C CC e C SC, que consistem essencialmente no mesmo tratamento, ou seja, novo plantio com preparo de solo convencional. Essas áreas apresentaram perdas de solo de 0,50 t.ha ${ }^{-1}$, distribuídas da seguinte forma: (a) na área adjacente ao trecho de estrada com conservação, foram constatadas perdas de 
0,18 t.ha $^{-1}$; (b) na área próxima ao trecho de estrada sem conservação, as perdas foram de 0,32 t.ha $^{-1}$; (c) no mês de dezembro de 2003, foi registrada a maior precipitação ocorrida durante o período, o que resultou em um incremento no volume de sedimentos transportados superior a $100 \%$, nesse tratamento, subindo de 0,14 t.ha ${ }^{-1}$ para 0,29 t.ha $^{-1}$. Esses sedimentos vinham sendo carreados para porções de maior declividade desse trecho de estrada durante eventos de chuva anteriormente ocorridos; e (d) nas áreas de contribuição próximas às divisoras ou aceiros, não foram constatadas perdas de solos durante o período.

Os valores de perda de solo obtidos através das áreas de contribuição adjacentes aos tratamentos de estrada também foram submetidos a análise estatística, da mesma forma que os tratamentos de estrada, e os resultados encontram-se expostos na tabela 4.

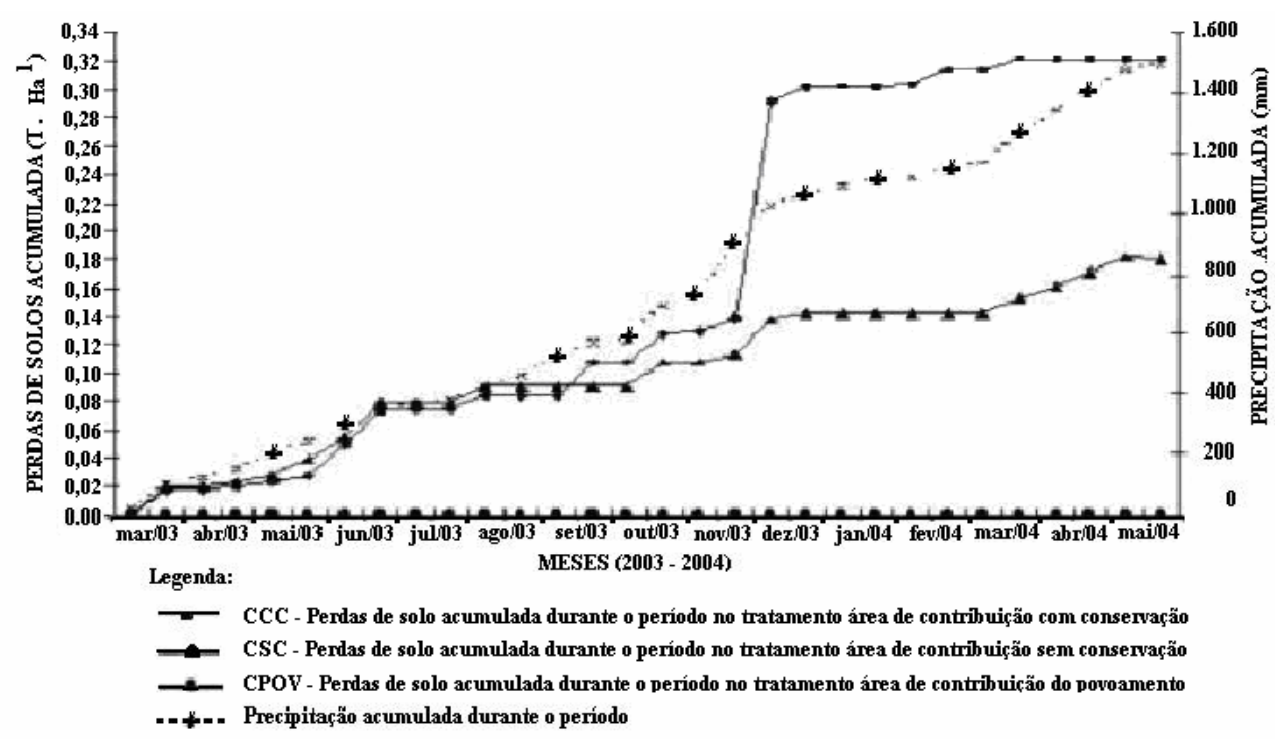

Figura 9. Precipitação acumulada versus perdas de solo acumuladas provenientes das áreas de contribuição nas UMFs de Itaiópolis (SC).

Figure 9. Accumulated precipitation versus accumulated soil losses originated from contribution areas in FMUs in Itaiopolis (SC).

Tabela 4. Análise estatística para as áreas de contribuição adjacentes aos trechos de estrada avaliados nas UMFs de Itaiópolis (SC).

Table 4. Statistical analyses for contribution areas adjacent at parts of forest roads evaluated at FMUs in Itaiópolis (SC).

\begin{tabular}{llccccc}
\hline Tratamento & Equação & $\mathbf{R}(\boldsymbol{\%})$ & $\mathbf{R}^{\mathbf{2}}(\boldsymbol{\%})$ & $\mathbf{F}(\mathbf{1 , 3})$ & $\mathbf{p}$ & Erro padrão \\
\hline C CC & ITA C / CC $=-0,0246+0,0003 * \mathrm{x}$ & 97,1 & 94,3 & 464,9 & $<0,001$ & 0,0304 \\
$\mathrm{C} \mathrm{SC}$ & ITA $/ \mathrm{C} / \mathrm{SC}=0,05264+0,00008 * \mathrm{x}$ & 97,5 & 95,0 & 534,6 & $<0,001$ & 0,0118 \\
\hline
\end{tabular}

$\mathrm{X}$ : variável precipitação acumulada no período.

Esses tratamentos apresentaram correlação superior a 97\% entre as perdas de solo acumuladas no período de avaliação e a precipitação acumulada. As equações propostas pela análise de regressão linear foram capazes de esclarecer de $94,3 \%$ a $95 \%$ as perdas de solo ocorridas nessas áreas durante o período de monitoramento, em função da precipitação acumulada, considerando uma margem de erro estimada inferior a 0,030. O controle da precipitação forneceu informações de perdas de solo acumuladas no período com alta significância estatística, em função dos valores de $\mathrm{F}(1,3)$ e p observados, considerando um intervalo de confiança de $95 \%$. A figura 10 expõe o comportamento das perdas de solo provenientes das áreas adjacentes aos trechos de estradas avaliadas durante o período em função da precipitação, através da análise de regressão linear nessas UMFs. 
C CC - Área de Contribuição com Conservação / Contribution Área with Conservation

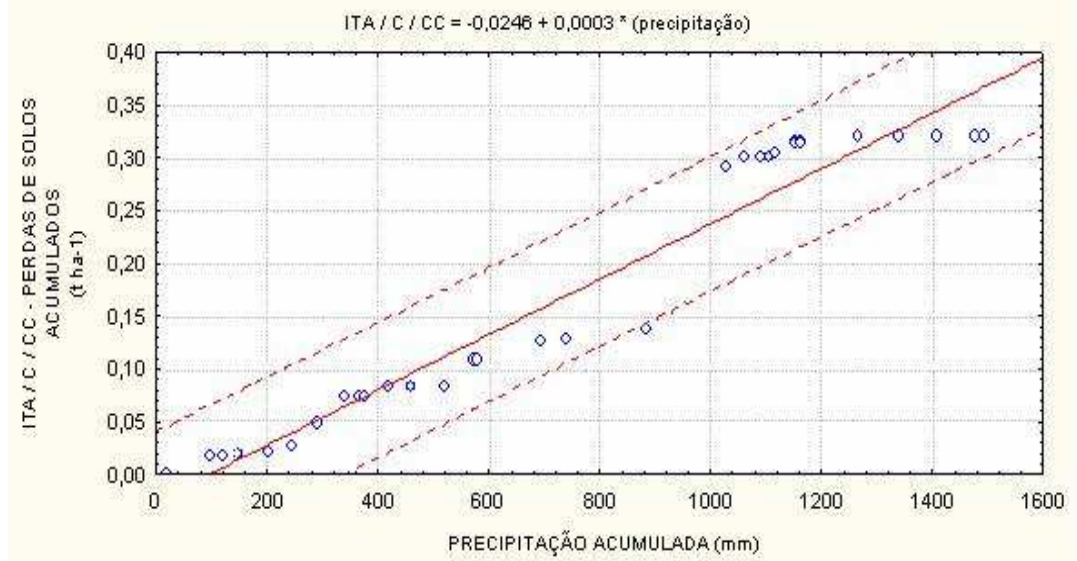

C SC - Área de Contribuição sem Conservação / Contribution Área without Conservation

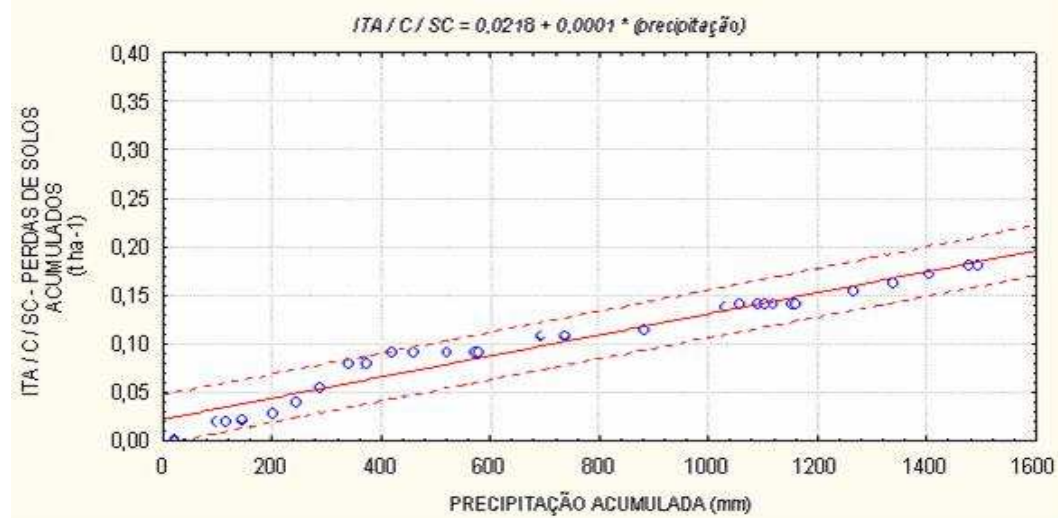

Figura 10. Precipitação acumulada versus perdas de solo acumuladas nas áreas de contribuição adjacentes aos trechos de estrada avaliados nas UMFs de Itaiópolis (SC).

Figure 10. Accumulated precipitation versus accumulated soil losses in contribution area adjacent at parts of forest roads evaluated at FMUs in Itaiopolis (SC).

A influência da precipitação como principal agente em processo erosivo observada neste trabalho já foi referenciada por diversos autores (BRADY; WEIL, 1999; BERTOL et al., 2002; FUJIHARA, 2002). Dessa forma, as equações propostas pela análise de regressão linear possibilitaram estimar as perdas anuais de solo da precipitação acumulada nos tipos de estradas avaliados, oferecendo elevado nível de ajuste com confiabilidade de $95 \%$.

Os eventos de chuva acumulados no período correspondem à precipitação acima de $10 \mathrm{~mm} \cdot \mathrm{h}^{-1}$. No entanto deve-se considerar ainda que o potencial erosivo das chuvas está relacionado com a intensidade máxima superior a $24 \mathrm{~mm} \cdot \mathrm{h}^{-1}$ em quinze minutos de chuva e que apresente energia cinética superior a 3,6 MJ, ou seja, somente os eventos de chuva com potencial de erosividade foram considerados nesse trabalho.

A ausência de perdas de solo, assim como de água nas áreas de contribuição adjacentes às estradas dos povoamentos ou divisoras, representados pelo tratamento C POV, pode ser atribuída ao fato de que a cobertura vegetal absorve a energia cinética da chuva, responsável pelo processo de desagregação do solo (LOMBARDI NETO et al., 1988), e a serapilheira formada dificulta o transporte de sedimentos.

As empresas da área florestal que não dispuserem de dados sobre precipitação, poderão ter acesso a eles através de órgãos como Simepar (no Paraná) e Epagri (em Santa Catarina), entre outros, o que se torna uma alternativa técnica prática acessível para se estimarem perdas de solo em estradas. 


\section{CONCLUSÃO}

- O monitoramento das perdas de solo pelo período de um ano admite o ajuste de equações que permitem estimar as perdas anuais de solo por processo erosivo em diferentes condições de estradas e características de solo e relevo, em função da precipitação acumulada.

- O monitoramento permitiu identificar o decréscimo de $11,9 \%$ das perdas de solo por processo erosivo em função das medidas de conservação de estradas adotadas pela empresa, resultando uma redução anual das perdas de solo em torno de $38 \mathrm{t}$.

- A densidade de estradas nas UMFs avaliadas apresentou-se dentro do limite máximo recomendado para efeito de certificação florestal, que admite até $60 \mathrm{~m} \cdot \mathrm{ha}^{-1}$, parâmetro que está diretamente relacionado com a maior incidência de processos erosivos em estradas.

- Outros parâmetros técnicos das estradas colaboraram para a ocorrência de processos erosivos nas estradas avaliadas, como o perfil longitudinal, o sistema de drenagem e o revestimento do leito. Portanto é necessário que as medidas de conservação sejam melhor dimensionadas e que a manutenção ocorra de forma mais frequente.

\section{REFERÊNCIAS}

BERTOL, I. Índice de erosividade $\left(\mathrm{EI}_{30}\right)$ para Lages $(\mathrm{SC})$ - $1^{\mathrm{a}}$ Aproximação. Pesquisa Agropecuária Brasileira, Brasília, DF, v. 28. n. 4. p. 515 - 521, abr. 1993.

BERTOL, I. Avaliação da erosividade da chuva na localidade de Campos Novos (SC) no período de 1981-1990. Pesquisa Agropecuária Brasileira, Brasília, DF, v. 29. n. 9. p. 1453 - 1458, set. 1994.

BERTOL, I.; SCHICK, J.; BATISTELA, O.; LEITE, D.; VISENTIN, D.; COGO, N. P. Erosividade das chuvas e sua distribuição entre 1989 e 1998, no município de Lages / SC. Revista Brasileira de Ciência do Solo, Viçosa, MG, v. 26, p. 455-464, 2002.

BRADY, N. C.; WEIL, R. R. The nature and properties of soils. 12. ed. New Jersey: Prentice Hall, 1999. $881 \mathrm{p}$.

CAMARGO CORREAA, C. M.; ROLOFF, G.; MALINOVSKI, J. R. Parameters of quality of the water originating from forest roads in Brazil. In: SOIL AND WATER CONSERVATION SOCIETY. Annual Conference, 2005, Rochester / NY. [Prroceedings...]. Iowa: CRC, 2005.

CAMARGo CORRÊA, C. M. Perdas de solo e a qualidade da água procedente de estrada de uso florestal no planalto catarinenese. 2005. 155 p. Tese (Doutorado em Ciências Florestais). Universidade Federal do Paraná. Curitiba. Paraná. Dezembro 2005.

CHRISTOPHER Jr., E. A. Post harvesting evaluation of best management practices for the prevention of soil erosion in Virginia. 125 p. Master of Science in Forestry. Virginia Polytechnic Institute and State University, Blacksburg, 2002.

DADALTO, D. D.; CARMO FILHO, O. G.; CASTRO, L. L. F. Captação de águas pluviais das estradas vicinais. Vitória: EMCAPA, 1990. p. 1-22. (Documentos, n. 63).

DENARDIN, J. E. Erodibilidade de solo estimada por meio de parâmetros físicos e químicos. 81 p. Tese (Doutorado) - Escola Superior de Agricultura "Luiz de Queiroz", Universidade de São Paulo, Piracicaba, 1990.

DISSMEYER, G. E.; FOSTER, G. R. A guide for predicting sheet and rill erosion on forest land. Asheville, N. C.: Southeastern Forest Experiment Station and Southeastern Area, State \& Private Forestry Atlanta, 1980. (Technical Publication SA-TP-11).

EMBRAPA CENTRO NACIONAL DE PESQUISAS DO SOLO. Manual de métodos de análise de solos. 2. ed. Rio de Janeiro: EMBRAPA Solos. 1997. 212 p.

FOSTER, G. R.; McCOOL, D. K.; RENARD, K. G.; MOLDENHAUER, W. C. Conversion of the universal soil loss equation to SI metric units. Journal Soil Water Conseration, Baltimore, v. 36, p. 355-359, 1981. 
FUJIHARA, A. K. Predição de erosão e capacidade de uso do solo numa microbacia do oeste paulista com suporte de geoprocessamento. 136 p. Dissertação (Mestrado em Ciência Florestal). Escola Superior de Agricultura "Luiz de Queiroz", Universidade de São Paulo, Piracicaba, 2002.

GARCIA, A. R.; MACHADO, C. C.; SILVA, E.; SOUZA, A. P. de; PEREIRA, R. S. Volume de enxurrada e perda de solo em estradas florestais em condições de chuva natural. Revista Arvore. Viçosa, MG, v. 17, n. 4, 2003.

LIRA FILHO, J. A.; SOUZA, A. P. Avaliação do impacto da exploração florestal no meio ambiente. In: SIMPÓSIO BRASILEIRO SOBRE EXPLORAÇÃO E TRANSPORTE FLORESTAL, 1., 1991, Viçosa, MG. Anais do... Viçosa, MG: SIF, 1991. p. 94-112.

LUCE, C. H. Proposal for a study on sediment production from forest roads under natural rainfall conditions. Moscow: USDA. Forest Service Intermountain Research Station, 1993. 7 p.

MACHADO, C. C.; GARCIA, A. R.; SILVA, E.; FONTES, A. M. Comparação de Taxas de Erosão em Estradas Florestais Estimadas pelo Modelo Wepp (Water Erosion Prediction Project) Modificado em Relação a Medições Experimentais. Revista Árvore, Viçosa, MG, v. 27, n. 3, p. 295-300, 2003.

MALINOVSKI, J. R.; CARVALHO, L. C.; CARVALHO, M. Planejamento de rede viária. Relatório técnico Klabin. 2004.

MANNIGEL, A. R.; CARVALHO, M. P.; MORETI, D.; MEDEIROS, L. R. Fator erodibilidade e tolerância de perda dos solos do Estado de São Paulo. Acta Scientiarum, Maringá, v. 24, n. 5, p. 1335$1340,2002$.

MAPA geológico do estado de Santa Catarina. Brasília, DF: Ministério das Minas e Energia. Secretaria da Ciência e Tecnologia, Minas e Energia. Coordenadoria dos Recursos Minerais, 1986.

NEVES, S.; NEVES, R.; FORNELOS, L. Aplicação de imagens do Radar Interferométrico (SRTM) na avaliação da fragilidade da bacia do Córrego Cachoeirinha, nos municípios de Cáceres e Porto Estrela /MT. Revista Geográfica Acadêmica, Goiânia, n. 2. v. 2. p. 124-137, 2008.

PARSONS, D. A. Coshocton - Type runoff samplers. Washington, DC: Laboratory investigations. United States Departament of Agriculture. Soil Conservation Service, 1954. 16 p.

PINTO, L. M. Relatório sumários de avaliação do sistema d manejo florestal da RIGESA Celulose Papel e Embalagens Ltda nos estados de Santa Catarina e Paraná: 2005. 52 p.

RANZINI, M. Balanço hídrico, ciclagem geoquímica de nutrientes e perdas de solo em duas microbacias reflorestadas com E. saligna Smith no Vale do Paraíba. 110 p. Dissertação (Mestrado em Hirdologia Florestal) - Escola Superior de Agricultura "Luiz de Queiroz", Universidade de São Paulo. Piracicaba, 1990.

ROLOFF, G. P.; DENARDIN, J. E. . Estimativa simplificada da erodibilidade do solo. In: REUNIÃO BRASILEIRA DE MANEJO E CONSERVAÇÃO DO SOLO E DA ÁGUA, 10., 1994, Florianópolis. Anais da... Florianópolis: Sociedade Brasileira de Ciência do Solo, 1994. p. 146-147.

SÁ, M. A. C. de; LIMA, J. M.; CURI, N.; MASSAROTO, J. A.; GRANATE DE SÁ, J. J.; MARQUES, M. Estimativa da erodibilidade pela desagregação por ultra-som e atributos de solos com horizonte B textural. Pesquisa Agropecuária Brasileira, Brasília, DF, v. 39, n. 7. p. 691 - 699. Jul.-jun., 2004.

SOUZA, C. K.; MARQUES JUNIOR, J.; MARTINS FILHO, M. V. PEREIRA, G. T. Influência do relevo e erosão na variabilidade espacial de um Latossolo em Jaboticabal - SP. Revista Brasileira de Ciências do Solo. Viçosa, MG, v. 27, n. 6, p. 1067-1074, 2003.

VITAL, A. R. T.; LIMA, W. P.; CAMARGO, F. R. A. Efeitos do corte raso de plantações de Eucalptus sobre o balanço hídrico, a qualidade da água e as perdas de solo e de nutrientes numa microbacia no Vale do Paraíba. SP. Scientia Forestalis, Piracicaba, n. 55, p. 5-16, jun. 1999.

WISCHMEIER, W. H.; SMITH. D. D. Rainfall energy and its relationship to soil loss. Transactions / American Geophysical Union, Washington, DC, v. 39. p. 285 - 291, 1958. 